astronomical and geographical knowledge is but of recent date, and, as already stated, Dante formed many of his cosmographic conceptions chiefly from hearsay.

N. PERINI

\section{The Horse-Power given to any Part of a Circuit by Intermittent Light}

Some time ago, with Prof. Ayrton, I designed and constructed an instrument to measure the horse-power given electrically to any incandescent or arc lamp, or to any part of a circuit, an improvement on the instrument previously devised by M. Deprez; the pointer of a suspendt $d$ coil moves at once to a mark on a scale which tells the horse-power. The instrument is dead beat, and, what is very important, by a special commutator arrangement it can be calibrated with much smaller forces than it is intended to measure. The current in the suspended coil is proportional to the difference of potential at the ends of a part of the circuit, and the fixed current which causes its deflection is the total main current in the circuit, so that the deflection represents the product of these two factors. The instrument was described at the Society of Arts in March last, and was exbibited at the British Association meeting at York. It will, however, necessarily only work accurately with non-reversed currents because of the self-induction of the suspended coil of fine wire, and it is very important to be able to maker the same measurement for reversed currents.

At the Electrical Congress at Paris, soon after the reading of M. Joubert's paper, in which he showed how to measure the mean value of the square of the difference of potential at two ends of a part of a circuit in which reversed currents are flowing, Prof. Ayrton described to me a method of performing the measurement of the horse-power for reversed currents which seemed to have suggested itself to him and to Prof. Fitzgerald of Dublin simultaneously when hearing M. Joubert's paper. It was this : Let there be three points in the circuit at potentials $V_{1}, V_{2}, V_{3}$,

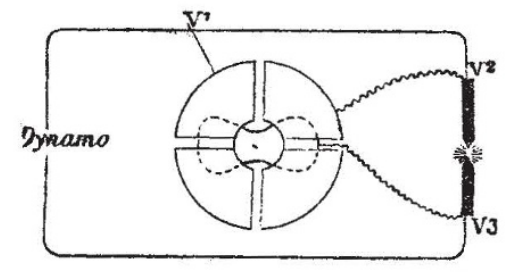

at any instant, and let there be a known resistance $R$ (with no self-induction) between $V_{1}$ and $V_{2}$. Let $V_{3}$ be connected with the needle of a Thomson's electrometer, and let $V_{1}$ and $V_{2}$ be connected with the quadrants, $V_{1}$ being also connected with the outside of the Leyden jar: then the deflection of the needle measures the mean value of

$$
\left(V_{2}-V_{1}\right)\left(V_{3}-\frac{V_{2}+V_{1}}{2}\right) \text {. }
$$

Now let the needle and a pair of quadrants be connected with $V_{2}$, the other pair with $V_{1}$, and we measure the mean value of the square of $\left(V_{2}-V_{1}\right)$. The difference of these measurements is easily seen to be $R$ times the expended energy which we want to know.

I was not present when Professors Ayrton and Fitzgerald communicated their idea to one another, but immediately afterwards Prof. Ayrton explained it to Sir William Thomson and to me together, making sketches of the necessary connections. Sir William thought well of it, but feared that perhaps the present quadrant electrometer would not be sensitive enough for the measurements. We suggested, however, the use of our multireflex arrangement (see La Lumière Electrique, October 5, 188I) for creating greater sensitiveness, and as he was pleased with the idea, we have, since that time, in our very short intervals of leisure, been trying to arrange an electrometer which shall be sensitive enough for the purpose.

I observed to-day that M. Potier in the October number of the Fournal de Physique publishes the same idea, and I wish to place it on record that the fundamental idea of the new process, which seems to me very feasible and of considerable practical importance, occurred to Messrs. Ayrton, Fitzgerald, and Potier independently.

Talgarth Road, West Kensington, I)ecember 6

\section{The New Red Star in Cygnus}

THE above star, which I found on the 22nd of May last, and which then appeared of the 9 th magnitude, and reached $8 \mathrm{~m}$. on June 8 , seems now no more than $12 \mathrm{~m}$. Estimations of very small magnitudes are, of course, very difficult, but I believe I am not under the mark in saying $12 \mathrm{~m}$., as I found the star not easy with a $4 \frac{1}{2}$.inch O.G. At the same time its deep crimson seemed very striking by glimpses, and in its present state it is, perhaps, the smallest among the stars whose red colour has been observed. It will probably have to be classed among the most remarkable variables.

J. BIRMINGHAM

\section{Meteor}

TAKING a look at the eclipse of the moon on December 5, about 5.44 p.m., I happened to see a meteor that is, I think, very noteworthy, though, perhaps from distance, its apparent size was so small that I might have scarcely seen it but for the temporary lessening of the light of the moon. Its motion was, throughout its visible course, horizontal and slow. When it met my eyes, it was just below the Pleiades. I followed its flight to the northern end of the eastern sky; there it seemed to go on out of my sight, without fall or collapse : for aught I know, I might have observed it even from the extreme south, had my eyes been turned thither at the outset; I would draw attention to this fact, as well as to its horizontal motion and its seemingly slow progress. The grandeur of the glories displayed by that night's clear sky was at its height as this mysterious stranger passed above our winsome satellite-then a thing of "eerie beauty," its glistening golden ring half-clasping, like "the old moon in the new moon's arms," the earth-shadowed orb over it, and the latter shimmering with the maroon ember-like sheen called by the French la lumière cendrée.

JOHN HOSKYNS-ABRAHALL

Combe Vicarage, near Woodstock, December I6

SEA-SiCkNESS. - This must be declined as a subject for correspondence.

A NEW ELECTRICAL STORAGE BATTERY'

T $H E$ great utility of some thoroughly practical method of conserving electric force has caused a great deal of attention to be applied to the subject; no system of electric supply can be considered as perfect until some means is used to so store the force generated that it may be drawn off equally and regularly, and this whether the generator be on or off. If we take, as an example of electric supply, the present systems of electric lighting, it is at once seen, should an accident or stoppage take place in the machinery generating the current, the whole of the apparatus such as lamps or motor-machines are influenced ; should there be a reservoir of electricity between the generator and the apparatus of whatever sort for utilising the force this inconvenience would not occur.

All the present systems of storing electricity depend on certain chemical changes produced by electrolysis.

I have gone through a long series of experiments on storing electricity and made many forms of cells, one being a porous pot containing dilute hydric sulphate and a sheet of lead, in an outer vessel containing a sheet of lead in solution of acetate of lead, the plate in the porous pot being made the positive electrode; this cell had the power of storing electricity, by peroxidising the positive electrode, and depositing from the acetate of lead solution metallic lead on the negative electrode, the hydrogen having combined to form acetic acid. On discharging the peroxide is reduced, and the oxide formed during discharge on the other plate dissolves in the acetic acid, forming the original solution of acetate of lead; by this means I eliminated the injurious effects of the hydrogen on charging.

During my experiments I found that red oxide of lead is a very bad conductor of electricity, and the peroxide a good conductor. I also discovered that by amalgamating lead plates with mercury a marked increase was x "On a New Electrical Storage Battery." By Henry Sutton (Ballarat V:ctoria). Communicated to the Royal Scciety by the President. 
immediately manifest in polarisation effects, the plates becoming more uniformly and rapidly peroxidised when used as positive electrodes, and local action entirely disappearing. These mercury amalgamated plates at once give me an advance of other cells. I used them in many ways, constructing cells in which the positive plate was amalgamated, and the negative coated with red oxide, or with peroxide, produced by treating red oxide with dilute hydric nitrate till the brown precipitate of peroxide fell, the precipitate being washed and painted on the electrode. I also amalgamated the negative electrode simply. I found that in every way positive electrodes amalgamated produced the best results. I also made cells in which either peroxide or red oxide was formed into a porous conglomerate, using the conglomerates as electrodes, immersed in dilute hydric'sulphate. I constructed cells with parallel plates, red oxide or peroxide being filled in between the plates; in this experiment red oxide is useless and peroxide efficient. In all these experiments I succeeded in storing electricity to different extents.

Having thoroughly satisfied myself that positive electrodes amalgamated with mercury were the best, I investigated the behaviour of various forms of negative electrode, having in view the conservation of the hydrogen; this I thought to do by occluding the hydrogen in suitable electrodes, as spongy platinum or metallic palladium; but as both these methods would be useless owing to expense I did not even experiment on them.

I further thought of having negative electrodes, whose oxides should be soluble in the solution, and which could be redeposited from the solution, or of having metallic solutions from which metal could be deposited, the resulting solution being such that should, on the oxidation of the deposited metal, combine with the oxide and again form the original solution.

I thought that success in this manner would result in a powerful and constant source of stored energy, the cell would not polarise itself during discharge, as is the case in both Planté and Faure cells; in these cells the peroxide formed by the discbarge produces a contrary electromotive force.

Experimenting from this train of thought, the results I have obtained are such as to have an important practical bearing on the future of electric work.

The experiments comprised amalgamated lead as a positive electrode with negative electrodes composed of either zinc, iron, or copper, in each case the solution between the electrodes being a salt of the metal composing the negative electrode. With zinc, sulphate of zinc was the solution; with iron, sulphate of iron; and with copper, sulphate of copper. In all these cases the results were not only far more powerful than with any form of cell I had previously devised, but also very constant, the polarisation lasting many times longer than in any other form of cell. The cell with zinc negative electrode I discarded, owing to the necessity there would be to keep the zinc plate amalgamated to prevent local action; the iron negative electrode was set aside owing to the iron oxidising when the cell was not in use. The cell having a negative electrode of copper, a positive electrode of lead amalgamated with mercury and a solution of cupric sulphate, I have adopted as a thoroughly economical, lasting, and practical form of storage reservoir. The chemical changes in this cell are exceedingly interesting and beautiful, the cell being composed of a sheet of lead cleaned with dilute sulphuric acid and amalgamated thoroughly with mercury, and a sheet of thin copper a little shorter; the two sheets are perforated with a number of holes and then rolled in a spiral, separated by rubber bands cut every five inches, the holes in plates and cuts in rubber bands being to allow free circulation of the solution (the short plate being uppermost before rolling). This combination is immersed in a solution of cupric sulphate, and the amalgamated lead plate made the positive electrode of a suitable source of electricity, the chemical action being that the oxygen of the decomposed solution combines with the lead, forming a perfectly even coating of the insoluble peroxide, the hydrogen replacing the copper of the solution, and the copper being deposited in the metallic state on the negative electrode. As the decomposition of the cupric sulphate proceeds the solution gradually loses its azure blue colour, becoming more acid, and finally when the whole of the copper is deposited, we have the solution colourless and transformed into hydric sulphate and water, the positive electrode peroxidised and copper deposited on the negative electrode. During discharge the peroxide is reduced and the copper element oxidised, the oxide combining with the acid and forming cupric sulphate, the solution re turning to its original colour. This change of colour forms a beautiful means of telling when the cell is charged; it is a veritable charging gauge. The power of this cell is very great and very constant; it can be made to last for hours, the time being dependent on the quantity of cupric sulphate decomposed.

I have, by the decomposition and recomposition of one pint of cupric sulphate, obtained over two hours' effective work in heating to a red heat one inch of No. 28 iron wire, the cell measuring internally 4 inches deep and 4 inches diameter.

I constructed cells with free crystals of cupric sulphate suspended in the solution, and found that the presence of free crystals prevented the oxidation of the amalgamated lead electrode, it being essential that the solution become slightly acid before the peroxide will form. The cell during charging gives out a peculiar rattling noise, which I consider due to the deposition of copper on the negative electrode altering the form of the spiral.

A practical form of cell for storing purposes ought to be made, by fixing a series of amalgamated lead plates in a box in grooves, as in Cruikshank's trough battery, filling the interval between the plates with solution of cupric sulphate, and passing a current through of sufficient tension to overcome the contrary electromotive force of the series, the positive sides of the plates being peroxidised and copper deposited on the negative sides. I have two boxes on this plan, each containing twentyfive plates, the total being equivalent to fifty cells. By this means batteries of great tension can be charged from thirty Bunsens. A number of twenty-five plate boxes can be coup'ed for quantity of charging, and for tension during discharge. Twenty such boxes, one foot square, internal measurement, will give in series a battery of 500 pairs of one foot square plates.

It will be seen from the foregoing that this method of conserving energy has a wide field before it, and as it will benefit fellow-workers in science, placing in their hands a means of experimenting with powerful electric currents, I give it without reservation, freely and untrammelled by patent rights, for their use.

\section{THE BISCHOFFSHEIM OBSERVATORY}

THIS observatory built at the expense of M. R. Bischoffsheim, the member of the French Lower House for Nice, is situated on Mont Gros, at an altitude of about 370 metres, and at a distance of eight English miles on the old Route de la Corniche, so well known and appreciated by the tourists travelling by road from Nice to Genoa. M. Celora, Milan astronomer, Commander Bahat of the French Staff, and M. Perrotin, the present director of theBischoffsheim Observatory, have ascertained electrically and astronomically, the longitude and latitude of the new establishment which has been connected with Paris and Milan, by unquestionable observations.

The buildings have been constructed under the direct supervision of M. Garnier, the architect of the Paris 